in vivo $34: 2217-2223(2020)$

doi:10.21873/invivo.12032

Review

\title{
Nuchal-type Fibroma: Single-Center Experience and Systematic Literature Review
}

\author{
IOANNIS D. KOSTAKIS ${ }^{1 *}$, THEMISTOKLIS FERETIS ${ }^{2 *}$, CHRISTOS DAMASKOS ${ }^{3,4^{*}}$, \\ NIKOLAOS GARMPIS ${ }^{4,5}$, GEORGE LIAPIS $^{6}$, IOANNIS PATERAS $^{6}$, ANNA GARMPI $^{7}$, \\ VASILIKI E. GEORGAKOPOULOU ${ }^{8,9}$ and EFSTATHIOS A. ANTONIOU ${ }^{4,5}$ \\ ${ }^{1}$ Department of Transplantation, Guy's Hospital, Guy's and St Thomas' NHS Foundation Trust, London, U.K.; \\ ${ }^{2}$ First Department of Endoscopic Surgery, Metropolitan General Hospital, Athens, Greece; \\ ${ }^{3}$ Renal Transplantation Unit, Laiko General Hospital, Athens, Greece; \\ ${ }^{4}$ N.S. Christeas Laboratory of Experimental Surgery and Surgical Research, Medical School, \\ National and Kapodistrian University of Athens, Athens, Greece; \\ ${ }^{5}$ Second Department of Propedeutic Surgery, Laiko General Hospital, \\ Medical School, National and Kapodistrian University of Athens, Athens, Greece; \\ ${ }^{6}$ First Department of Pathology, Medical School, National and Kapodistrian University of Athens, Athens, Greece; \\ ${ }^{7}$ First Department of Propedeutic Internal Medicine, Laiko General Hospital, Medical School, \\ National and Kapodistrian University of Athens, Athens, Greece; \\ ${ }^{8}$ Department of Pulmonology, Laiko General Hospital, Athens, Greece; \\ ${ }^{9}$ First Department of Pulmonology, Sismanogleio Hospital, Athens, Greece
}

\begin{abstract}
Background: Nuchal-type fibroma is a rare benign tumor arising from the connective tissue. Our aim was to present our experience via two cases of this tumor and a comprehensive review of the literature. Patients and Methods: We report a case of a 23-year-old female with a mass located in the posterior neck and the upper back and a case of a 50-year-old male with a mass located in the posterior neck, which were proved to be nuchal-type fibromas in the histopathological examination. We also searched the PubMed/Medline database for published cases of nuchal-type fibromas. Results and Discussion: Nuchaltype fibroma is a rare benign tumor arising from the connective tissue, usually in the posterior neck, which affects
\end{abstract}

This article is freely accessible online.

*These Authors contributed equally to this study.

Correspondence to: Dr. Christos Damaskos, MD, MSc, Ph.D., Renal Transplantation Unit, Laiko General Hospital, N.S. Christeas Laboratory of Experimental Surgery and Surgical Research, Medical School, National and Kapodistrian University of Athens, 17 Agiou Thoma Street, Athens, 11527, Greece. Tel: +30 6948467790,e-mail: x_damaskos@yahoo.gr

Key Words: Nuchal, fibroma, tumor, CD34, review. different ages, with most patients being male. It is a poorly circumscribed tumor consisting of hypocellular, thick, dense and haphazardly arranged collagen bundles with entrapped adipocytes, nerve fibers and muscle fascicles and a few scattered spindle cells, which are CD34 positive. Its excision is curative, and the recurrence risk is generally low. However, patients with Gardner's syndrome may experience recurrence more frequently. Conclusion: Nuchal-type fibroma should be included in the differential diagnosis of subcutaneous, soft-tissue masses, especially when these involve the posterior neck.

Nuchal-type fibroma is a rare benign tumor arising from the connective tissue (1). It is usually located in the posterior neck (2-18) and affects different ages (5), with most patients being male (1-3, 5-13, 17, 19-29). Since the first description of nuchal-type fibroma by Enzinger and Weiss in 1988 (1), over than 100 cases have been reported in the literature (1-33).

Herein, we report a case of a 23-year-old female with a mass located in the posterior neck and the upper back and a case of a 50-year-old male with a mass located in the posterior neck. Both cases were proved to be nuchal-type fibromas in the histopathological examination. We present a review of all the reported cases of this entity in the literature. 

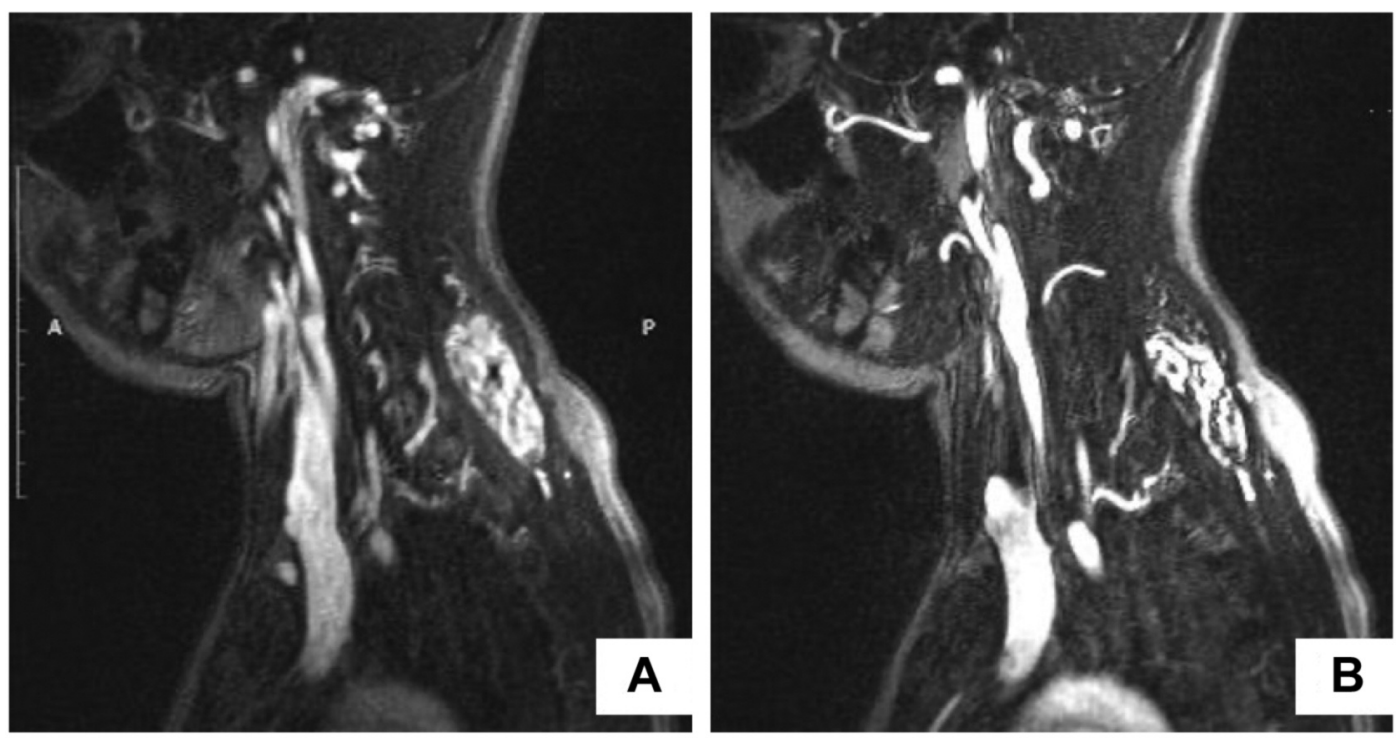

Figure 1. Magnetic resonance imaging (MRI) findings. A: MRI scan (T1 weighted sequence) showing two tumors with high signal intensity located in the posterior neck and the upper back; B: MRI scan (T1 weighted sequence) showing heterogeneous contrast enhancement of the larger tumor and homogeneous contrast enhancement of the smaller tumor.

\section{Patients and Methods}

\section{Cases presentation}

Case 1. A 23-year-old female was admitted to our department with a painless, firm, relatively fixed mass $5 \mathrm{~cm}$ in diameter that was located in the posterior neck and the upper back. The mass originally appeared six months earlier and had reportedly increased in size during the last two months. The patient underwent a magnetic resonance imaging (MRI) scan, which revealed the presence of a well-demarcated tumor $4.8 \mathrm{~cm}$ in diameter, between the left trapezius muscle and the left splenius muscle, and a small lipoma $2 \mathrm{~cm}$ in diameter, located superficially to the deeper lesion (Figure 1A). Both lesions demonstrated high signal intensity in T1 weighted MRI sequence, with heterogeneous contrast enhancement for the larger tumor and homogeneous contrast enhancement for the smaller tumor (Figure 1B). The patient underwent surgical excision of the tumors under general anesthesia. Her postoperative course was uneventful, and she was discharged from the hospital the next day. The macroscopic pathological examination of the surgical specimens revealed the presence of a poorly circumscribed, firm, yellow-white mass with fatty and fibrous areas which was $5 \mathrm{~cm} \times 2.5 \mathrm{~cm} \times 0.5 \mathrm{~cm}$ in dimensions for the larger lesion (Figure 2) and a well circumscribed, soft, yellow, fatty mass $2 \mathrm{~cm}$ in diameter for the smaller lesion. The histological examination of the larger tumor showed the presence of hypocellular dense collagen bundles with areas of entrapped adipocytes and nerve fibers. A few spindle cells without atypia were identified within the collagen bundles (Figure 3a). Immunohistochemistry demonstrated that these spindle cells were stained positive for CD34 (Figure 3b). The aforementioned histopathological features of the tumor supported the diagnosis of a nuchal-type fibroma. As far as the smaller tumor is concerned, it was a typical lipoma. No recurrence has been detected up to this point, thirty months after the lesion's excision.

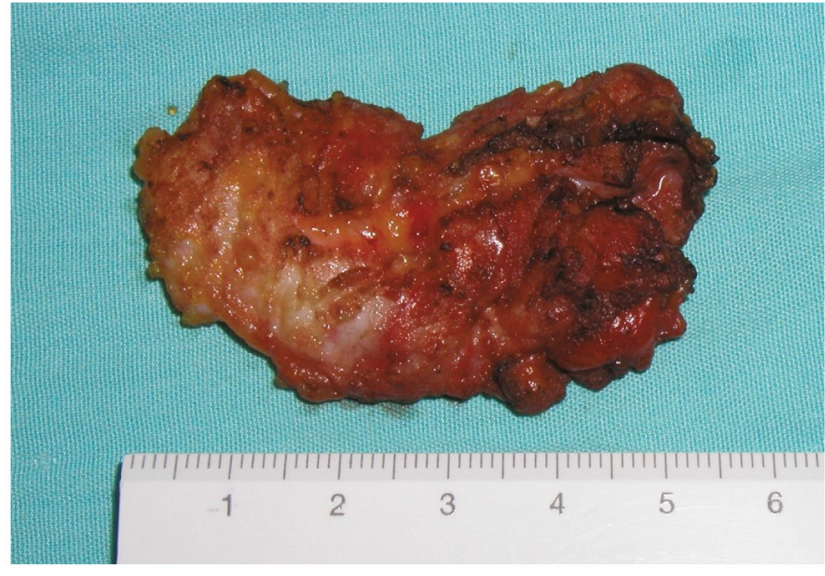

Figure 2. Macroscopic view of the surgical specimen.

Case 2. A 50-year-old male was also admitted to our department with a painless, firm, movable mass $2.5 \mathrm{~cm}$ in diameter that was located in the posterior neck. The mass had made its appearance two years earlier and had become larger during the last six months. The patient underwent surgical excision of the tumor under local anesthesia, with the clinical diagnosis of neck lipoma. The macroscopic pathological examination of the surgical specimen revealed the presence of a poorly circumscribed, firm, yellow-white mass with fatty and fibrous areas which was $2.5 \mathrm{~cm} \times 2.2 \mathrm{~cm} \times 1.2 \mathrm{~cm}$ in dimensions. The histological examination of the tumor showed the presence of dense collagen bundles mixed with adipocytes. A few spindle cells without atypia were identified within the collagen bundles (Figure 3C). Immunohistochemistry revealed that these spindle cells produced CD34. All these histopathological features 

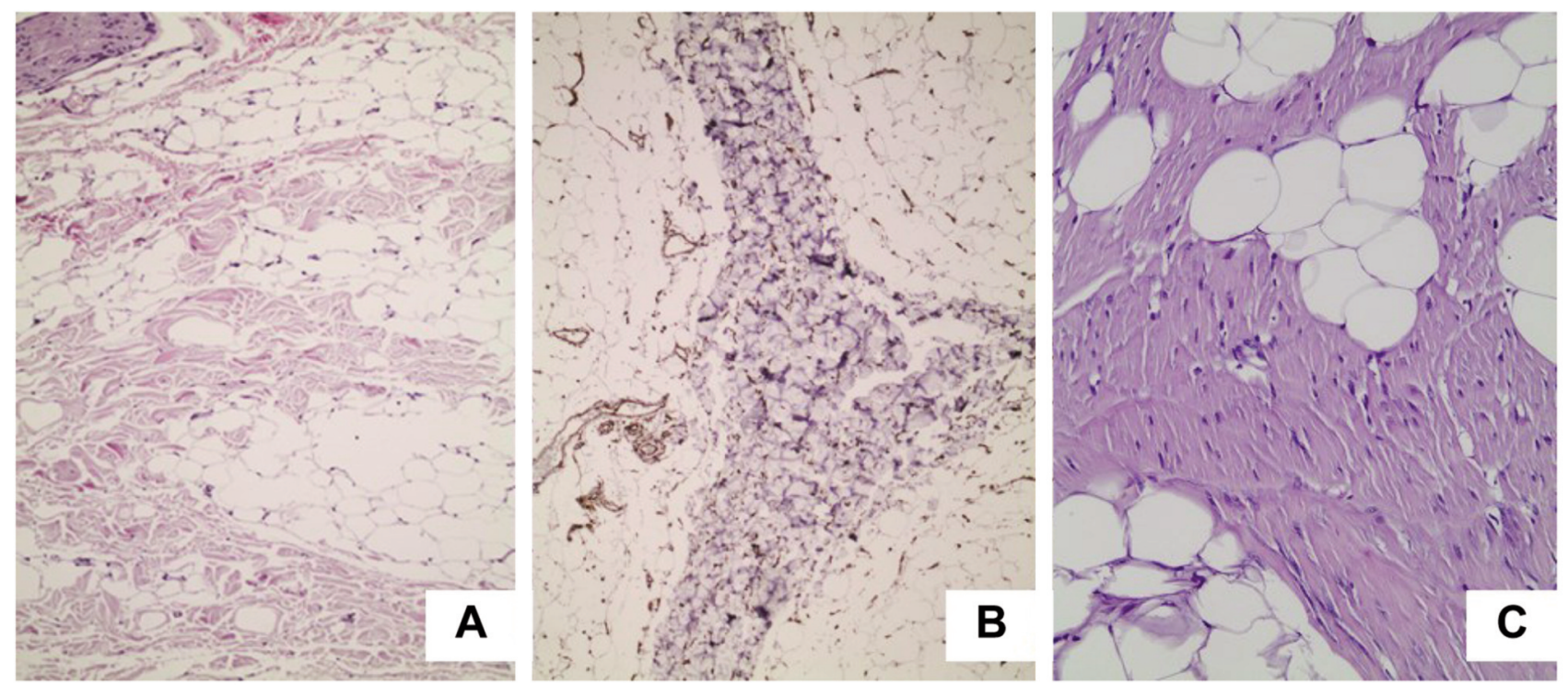

Figure 3. Microscopic view of the surgical specimen. A: Thick, haphazardly arranged collagen fibers with entrapped adipocytes and a few spindle cells (hematoxylin and eosin stain, 100x original magnification). B: Spindle cells stained positive for CD34 (100x original magnification). C: Microscopic view of the surgical specimen. Thick, haphazardly arranged collagen fibers with entrapped adipocytes and a few spindle cells (hematoxylin and eosin stain, 200x original magnification).

set the diagnosis of a nuchal-type fibroma. There was no recurrence twenty-two months after the lesion's excision.

Literature search. An extensive search of the PubMed Index was performed for published cases of nuchal-type fibromas using the following terms: "nuchal", "neck", "cervical", "nuchal-type" and "fibroma". Results were filtered for publications in English, concerning human subjects. All references from the identified publications were searched for other non-indexed cases.

Out of fifty tree publications, thirty-two manuscripts were finally included in this review (Figure 4). Some publications $(n=6)$ could not be electronically retrieved and were excluded. Fifteen were also excluded as they were earlier reviews of the literature.

\section{Results and Discussion}

We were able to identify 107 cases of nuchal-type fibroma in the existing literature, including the present cases (2-33). Most patients were male (1-3, 5-13, 17, 19-29). In particular, there were $82(76.6 \%)$ male and $25(23.4 \%)$ female patients $(2-9,11-22,24-26,30,31,33)$. Patient age in the reported cases varied greatly, ranging from 3 months to 80 years, with a mean age of 43.7 years (1-33). Most nuchal-type fibromas arose in the posterior neck $(2-9,11-18,23)$. However, other anatomic sites of origin were also reported less frequently, such as the back $(3,5,20-22)$ chest $(20,21)$, shoulder $(5,19$, $22,27,30,32)$, scapula $(2,5,19)$, thigh $(21)$, buttock $(25$, $31)$, scalp $(3,21,26)$, sacral region (28), mouth floor (33), eyebrow (29) and coccyx (23) (Table I). A nuchal-type fibroma usually presents itself as a subcutaneous, soft-tissue, firm mass $(3,5,6,8,12-19,21,25,29,32)$ that can be fixed or mobile $(6,8,11,14,16-28)$ and painless or mildly tender $(1,3,4,7,14,16-19,21,24-28,31,33)$ (Table II). A wide range of tumor sizes was reported, with tumor diameter ranging from $0.7 \mathrm{~cm}$ to $20 \mathrm{~cm}(1-5,7,9-11,13-16,18-24$, 27-29, 31-33). Most patients, specifically 95 out of 107 $(88.8 \%)$, presented with a single nuchal-type fibroma (1-13, $16-25,27,28,30-33)$. Cases with $2(5,14,15,21,22), 3$ (21), 4 (21) or even 6 fibromas (26) have also been reported (Table III).

There was an association between the appearance of nuchal-type fibromas and Gardner's syndrome $(5,7,20-22$, $25)$. Twenty out of the $107(18.7 \%)$ reported patients had Gardner's syndrome $(5,7,20-22,25,29)$. However, the majority of the patients, specifically 87 out of the 107 cases (81.3\%), had no medical history of this syndrome (1-6, 8-19, $21,23,24,26-28,30,31,33)$. It is noteworthy that out of the 12 patients with multiple fibromas $(5,10,14,15,21,22,26$, 29), $6(50.0 \%)$ had Gardner's syndrome $(5,21,22)$. Moreover, the majority of patients with nuchal-type fibromas and Gardner's syndrome were male [13/20 (65.0\%)]. Another interesting finding is that patients with Gardner's syndrome were younger (mean age: 15.6 years, range: 3 months - 60 years) $(5,7,20-22,25,29)$ than patients without (mean age: 40 years, range: 6 months - 74 years) $(1-6,8-19,21,23,24$, $26-28,30,31,33)$. Furthermore, in 6 cases nuchal-type fibroma was accompanied by diabetes mellitus $(4,5,33)$ and in 6 cases the fibroma reportedly presented at a site of 


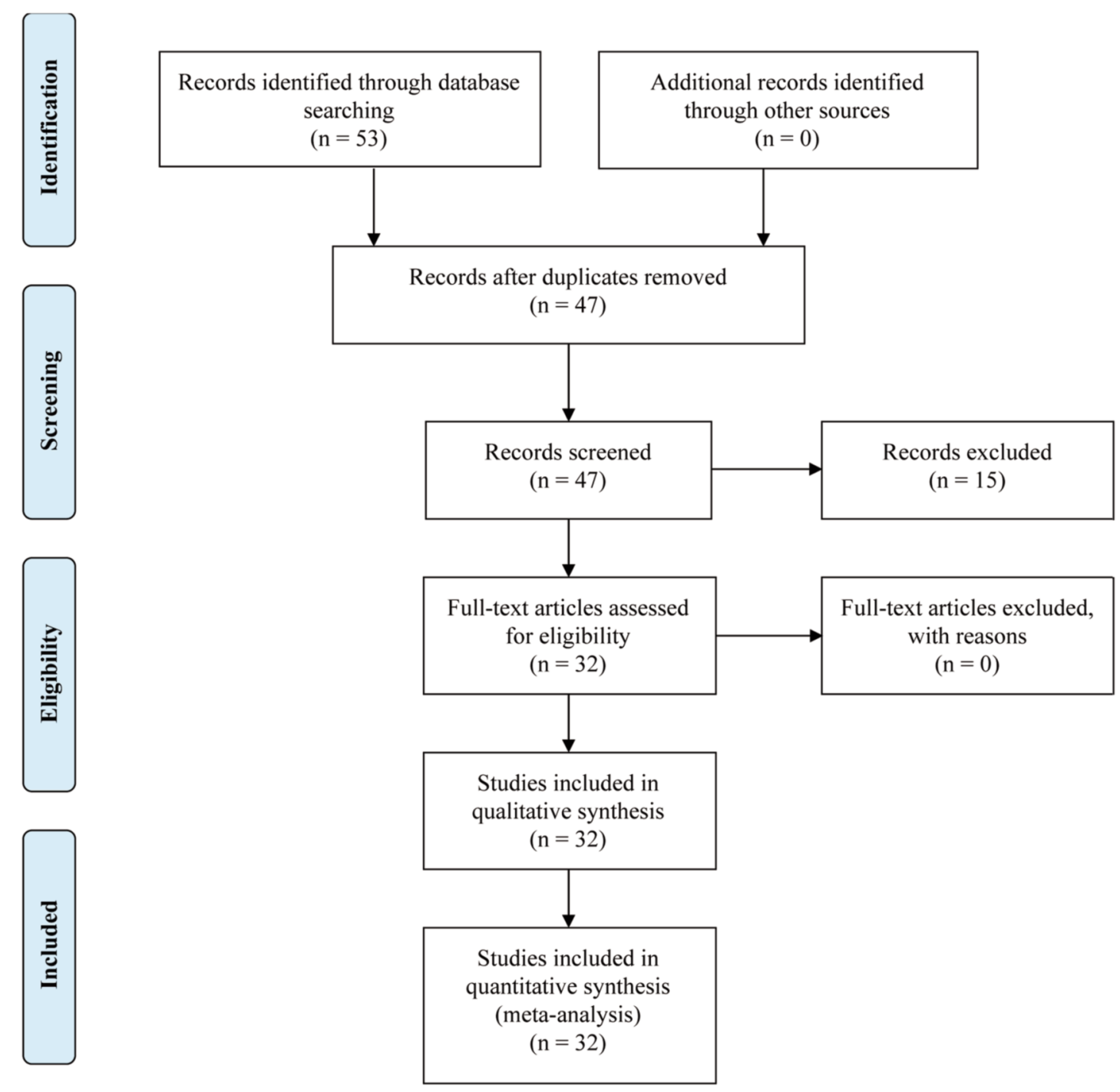

Figure 4. Macroscopic view of the surgical specimen.

previous trauma $(2,6,12,22,27,28)$. Table IV describes the coexistence of nuchal-type fibroma with other diseases.

In regard to the histopathological examination, there is a remarkable homogeneity of the findings among the various reported cases. The macroscopic examination of nuchal-type fibromas uniformly demonstrated circumscribed and firm masses $(5,8,9,20-22,28,32,33)$ of usually yellow and/or white color, corresponding to fatty and fibrous areas, respectively $(3-5,8-10,21,22,24,25,32)$. Microscopically, the specimen consisted of hypocellular, thick, dense and haphazardly arranged collagen bundles. Specifically, elastic fibers, entrapped nerve fibers, adipose tissue and muscle fascicles were present within the collagen bundles $(2-9,11$, 13-15, 17-22, 24-27, 30-32). There are a few elastic fibers $(3,5,8,11,20,22,24,25,30)$ and often entrapped nerve fibers, adipose tissue and muscle fascicles within the collagen bundles $(3,5,7,8,12-15,18-22,24-27,30,32)$. Sparsely scattered spindle cells could also be detected among the collagen fibers; the cells resembled fibroblasts with no evidence of atypia $(2,3,5,7,13,21,22,24-27,30,31)$. The immunohistochemical examination showed that these spindle cells were CD34 positive $(1,8,12,16,20-22,25,27-29,33)$ and smooth muscle actin (SMA) $(5,16,18-21,25,33)$, desmin $(5,18,21)$ and S100 negative in all cases $(5,19)$. However, as for vimentin $(3,5,16,21,22,25)$ and CD99 (8, $12,25)$, the literature is more controversial, with reports suggesting that nuchal-type fibromas may or may not express these markers $(16,21)$ (Table V).

Only a few reports focus on the findings of imaging studies in nuchal-type fibromas $(7,9,10,12,17-19,23,24,28,29$, 
Table I. Location of nuchal-type fibromas.

\begin{tabular}{lc}
\hline Location & Number of cases \\
\hline Neck & 32 \\
Back & 15 \\
Shoulder & 8 \\
Thigh & 1 \\
Chest & 3 \\
Face & 3 \\
Scalp & 5 \\
Scapular & 6 \\
Forearm & 1 \\
Knee & 1 \\
Truncal & 1 \\
Ear & 1 \\
Buttock & 2 \\
Ankle & 1 \\
Sacral & 1 \\
Mouth & 1 \\
Paraspinal & 1 \\
Coccyx & 5 \\
\end{tabular}

Table II. Number of patients presenting with specific symptoms and signs.

\begin{tabular}{lc}
\hline Presenting symptom & Number of patients \\
\hline Painful mass & 5 \\
Painless mass & 7 \\
Soft-tissue mass & 10 \\
Hard-tissue mass & 4 \\
Firm mass & 16 \\
Mobile mass & 5 \\
Asymptomatic & 6 \\
\hline
\end{tabular}

31-33). Two articles reported that a nuchal-type fibroma was depicted as a hypoechoic mass during a diagnostic ultrasound $(17,29)$. Moreover, another article reported a nuchal-type fibroma with high density and two articles reported wellcircumscribed masses on computed tomography $(9,29,33)$. In addition, there are also a few reports of patients with this type of tumor that underwent MRI scans. The respective lesions demonstrated low signal intensity on T1, T2, turbo inversion recovery magnitude (TIRM) and short inversion time inversion recovery (STIR) weighted MRI sequences $(7,19,23,24,29,31)$ with one tumor displaying homogeneous enhancement (31) and another tumor no enhancement after intravenous contrast administration (7). However, there was a case in which the tumor had mixed signal intensity in T1 and T2 weighted MRI sequences (32).

Data regarding patient surveillance were available in 51 out of the 107 reported cases $(3,5,11,16,17,21,22,24$, $25,27,32)$. Thirteen patients with available follow-up data
Table III. Number of patients categorized by the number of lesions.

\begin{tabular}{lc}
\hline Number of masses & Number of patients \\
\hline 1 & 95 \\
2 & 5 \\
3 & 2 \\
4 & 1 \\
6 & 1 \\
\hline
\end{tabular}

Table IV. Number of patients presenting Garner's syndrome, trauma, diabetes mellitus and scleredema.

\begin{tabular}{lc}
\hline Disease & Number of patients \\
\hline Garner's syndrome & 20 \\
Trauma & 4 \\
Diabetes Mellitus & 6 \\
Scleredema & 1 \\
\hline
\end{tabular}

Table V. Immunohistochemistry findings.

\begin{tabular}{lcc}
\hline Marker & $\begin{array}{c}\text { Number of } \\
\text { positive patients }\end{array}$ & $\begin{array}{c}\text { Number of } \\
\text { negative patients }\end{array}$ \\
\hline CD34 & 19 & 0 \\
SMA & 0 & 12 \\
CD99 & 5 & 1 \\
Vimentin & 11 & 4 \\
Desmin & 0 & 8 \\
MSA & 0 & 2 \\
ER & 0 & 6 \\
S100 & 0 & 3 \\
GFAC & 0 & 1 \\
EMA & 0 & 3 \\
$\beta$-catenin & 1 & 2 \\
Cyclin-D & 1 & 0 \\
Ki-67 & 0 & 1 \\
SMM & 0 & 1 \\
\hline
\end{tabular}

suffered from Gardner's syndrome $(5,21,22,25)$ while the remaining 38 did not $(3,5,11,16,17,24,27,32)$. Recurrence was reported in 9 out of 51 cases $(17.6 \%)(5$, $21)$. Interestingly, 4 out of 13 cases $(30.8 \%)$ of fibroma in patients with Gardner's syndrome recurred as desmoid tumors (21), whereas only 5 out of the 38 cases $(13.2 \%)$ without Gardner's syndrome experienced recurrence (5).

\section{Conclusion}

Our patients had typical nuchal-type fibromas. The only exception was perhaps the fact that the lesion in the 23-year- 
old female patient demonstrated high signal intensity in T1 weighted images of MRI scan with heterogeneous contrast enhancement. In conclusion, nuchal-type fibroma is a rare benign tumor arising from the connective tissue, usually in the posterior neck. It is a poorly circumscribed tumor consisting of hypocellular, thick, dense and haphazardly arranged collagen bundles with entrapped adipocytes, nerve fibers and muscle fascicles and a few scattered spindle cells, which are CD34 positive. Its excision is curative, and the recurrence risk is generally low. However, patients with Gardner's syndrome may experience recurrence more frequently. Nuchal-type fibroma should be included in the differential diagnosis of subcutaneous, soft-tissue masses, especially when these involve the posterior neck. Indications of the existence of a nuchal-type fibroma may be the location in the posterior neck and a compatible imaging study, especially when the mass is presented in a male patient or a patient with Gardner syndrome. Nevertheless, histological examination combined with immunohistochemistry is needed for definitive diagnosis.

\section{Conflicts of Interest}

All the Authors declare that there are no conflicts of interest regarding this study.

\section{Authors' Contributions}

IDK, CD and EAA designed the study. IDK, TF and CD wrote the article. IDK, TF, CD and NG collected the data. EAA performed the surgical operations. GL and IP performed the histopathological evaluations. CD and NG critically revised the manuscript and offered scientific advice. AG and VEG revised the manuscript. EAA was the supervisor.

\section{References}

1 Enzinger FM and Weiss SW: Benign tumors and tumorlike lesions of fibrous tissue. In: Soft Tissue Tumors, $2^{\text {nd }}$ Ed. Enzinger FM (ed.). St Louis, Mosby, pp 102-135, 1988.

2 Lister DM, Graham-Brown RA, Burns DA, Richardson RA and Milward TM: Collagenosis nuchae - A new entity? Clin Exp Dermatol 13(4): 263-264, 1988. PMID: 3246095. DOI: 10.1111/ j.1365-2230.1988.tb00696.x

3 Balachandran K, Allen PW and MacCormac LB: Nuchal fibroma. A clinicopathological study of nine cases. Am J Surg Pathol 19(3): 313-317, 1995. PMID: 7872429.

4 Abraham Z, Rozenbaum M, Rosner I, Naschitz Y, Boss Y and Rosenmann E: Nuchal fibroma. J Dermatol 24(4): 262-265, 1997. PMID: 9164070. DOI: 10.1111/j.1346-8138.1997. tb02786.x

5 Michal M, Fetsch JF, Hes O and Miettinen M: Nuchal-type fibroma: A clinicopathologic study of 52 cases. Cancer 85(1): 156-163, 1999. PMID: 9921988. DOI: 10.1002/(sici)10970142(19990101)85:1<156::aid-cncr22>3.0.co;2-o

6 Banney LA, Weedon D and Muir JB: Nuchal fibroma associated with scleredema, diabetes mellitus and organic solvent exposure.
Australas J Dermatol 41(1): 39-41, 2000. PMID: 10715899. DOI: $10.1046 / \mathrm{j} .1440-0960.2000 .00386 . x$

7 Dawes LC, La Hei ER, Tobias V, Kern I and Stening W: Nuchal fibroma should be recognized as a new extracolonic manifestation of Gardner-variant familial adenomatous polyposis. Aust N Z J Surg 70(11): 824-826, 2000. PMID: 11147449. DOI: 10.1046/j.1440-1622.2000.01958.x

8 Diwan $\mathrm{AH}$ and Horenstein MG: Dermatofibrosarcoma protuberans association with nuchal-type fibroma. J Cutan Pathol 31(1): 62-66, 2004. PMID: 14675287. DOI: 10.1046/ j.0303-6987.2004.0129.x

9 Tsunemi Y, Saeki H and Tamaki K: Nuchal fibroma clearly visualized by computed tomography: A case report. Int J Dermatol 44(8): 703-704, 2005. PMID: 16101884. DOI: 10.1111/j.1365-4632.2004.02388.x

10 Yokoyama S, Nakano H, Kaneko T and Hanada K: A Japanese case of nuchal-type fibroma. J Dermatol 32(11): 931-932, 2005. PMID: 16361759. DOI: 10.1111/j.1346-8138.2005.tb00876.x

11 Abe M, Nagai Y, Okada E, Aoyama K, Tamura A and Ishikawa O: Case of nuchal fibroma. J Dermatol 34(7): 498-500, 2007. PMID: 17584333. DOI: 10.1111/j.1346-8138.2007.00320.x

12 Hernández-Núñez A, Tardío JC, Castellano-Megias VM, Romero-Maté A and Borbujo J: Nuchal-type fibroma associated with lipoma and traumatic neuroma. J Eur Acad Dermatol Venereol 21(10): 1420-1422, 2007. PMID: 17958856. DOI: 10.1111/j.1468-3083.2007.02223.x

13 Karonidis A, Rigby HS and Orlando A: Collagenosis nuchae: A case report of a rare and often misdiagnosed condition. J Plast Reconstr Aesthet Surg 60(3): 320-323, 2007. PMID: 17293293. DOI: $10.1016 /$ j.bjps.2006.03.060

14 Lee SE, Kim YC and Kim SC:; Nuchal fibroma presenting as two posterior neck masses. J Dermatol 34(4): 262-263, 2007. PMID: 17352725. DOI: 10.1111/j.1346-8138.2007.00265.x

15 LeBlanc KG Jr, Wenner M and Davis LS: Multiple nuchal fibromas in a 2-year-old without Gardner syndrome. Pediatr Dermatol 28(6): 695-696, 2011. PMID: 21950671. DOI: 10.1111/j.1525-1470.2011.01415.x

16 Döngel I, Yazkan R, Duman L, Oztürk O and Kapucuoğlu FN: Huge inflammatory myofibroblastic tumor of pleura with concomitant nuchal fibroma. Ann Thorac Surg 96(4): 1461-1464, 2013. PMID: 24088461. DOI: 10.1016/j.athoracsur.2013.01.082

17 Møller M and Sørensen FB: Fibroma nuchae i nakkeregionen. Ugeskr Laeger 176: 50-51, 2014.

18 Alsaleh $\mathrm{N}$ and Amanguno H: Nuchal Fibroma: A rare entity of neck masses. Gulf J Oncolog 1(18): 10-12, 2015. PMID: 26003098.

19 Hameed M, Benevenia J, Blacksin M and Aisner SC: Nuchal fibroma of the shoulder involving skeletal muscle: A radiographic and clinicopathological study. A case report. J Bone Joint Surg Am 80(11): 1684-1686, 1998. PMID: 9840639. DOI: 10.2106/00004623-199811000-00017

20 Diwan AH, Graves ED, King JA and Horenstein MG: Nuchaltype fibroma in two related patients with Gardner's syndrome. Am J Surg Pathol 24(11): 1563-1567, 2000. PMID: 11075861. DOI: 10.1097/00000478-200011000-00015

21 Wehrli BM, Weiss SW, Yandow S and Coffin CM: Gardnerassociated fibromas (GAF) in young patients: A distinct fibrous lesion that identifies unsuspected Gardner syndrome and risk for fibromatosis. Am J Surg Pathol 25(5): 645-651, 2001. PMID: 11342777. DOI: 10.1097/00000478-200105000-00012 
22 Michal M, Boudova L and Mukensnabl P: Gardner's syndrome associated fibromas. Pathol Int 54(7): 523-526, 2004. PMID: 15189507. DOI: $10.1111 / \mathrm{j} .1440-1827.2004 .01660 . x$

23 Shin JB, Son SW and Kim IH: Nuchal-type fibroma of the coccyx. Ann Dermatol 20(1): 41-44, 2008. PMID: 27303158. DOI: $10.5021 /$ ad.2008.20.1.41

24 Sraj SA, Lahoud LE, Musharafieh R and Taha A: Nuchal-type fibroma of the ankle: A case report. J Foot Ankle Surg 47(4): 332-336, 2008. PMID: 18590898. DOI: 10.1053/j.jfas. 2008.03.004

25 Linos K, Sedivcová M, Cerna K, Sima R, Kazakov DV, Nazeer T, Glazyrin A, Valerian BT and Carlson JA: Extra nuchal-type fibroma associated with elastosis, traumatic neuroma, a rare APC gene missense mutation, and a very rare MUTYH gene polymorphism: A case report and review of the literature. J Cutan Pathol 38(11): 911-918, 2011. PMID: 21752055. DOI: 10.1111/j.1600-0560.2011.01745.x

26 Kim do H, Kim TH, Sung NH, Shin H, Lee AY and Lee SH: Multiple nuchal-type fibromas on the scalp: A case report. Ann Dermatol 27(2): 194-196, 2015. PMID: 25834360. DOI: 10.5021/ad.2015.27.2.194

27 Lee CC, Lai CS, Lin CH, Lin YN, Chu SC, Chai CY and Lee $\mathrm{CH}$ : Extra nuchal-type fibroma associated with repetitive blunt trauma during religious activities. Trauma Case Rep 4: 16-20, 2016. PMID: 29942846. DOI: 10.1016/j.tcr.2016.05.007

28 Lee JS and Mun JH: Asymptomatic solitary mass on the sacral region. Clin Exp Dermatol 44(5): 535-539, 2019. PMID: 30294793. DOI: $10.1111 /$ ced.13760
29 Kiessling P, Dowling E, Huang Y, Ho ML, Balakrishnan K, Weigel BJ, Highsmith WE Jr, Niu Z and Schimmenti LA: Identification of aggressive Gardner syndrome phenotype associated with a de novo APC variant, c.4666dup. Cold Spring Harb Mol Case Stud 5(2): a003640, 2019. PMID: 30696621. DOI: $10.1101 / \mathrm{mcs} . \mathrm{a} 003640$

30 Schiller PI, Kunte C, Sander CA and Kind P: Nuchales fibrom. Hautarzt 48(10): 759-761, 1997. PMID: 9441171. DOI: $10.1007 / \mathrm{s} 001050050657$

31 Lee GK, Suh KJ, Lee SM and Lee SJ: Nuchal-type fibroma of the buttock: Magnetic resonance imaging findings. Jpn J Radiol 28(7): 538-541, 2010. PMID: 20799020. DOI: 10.1007/s11604010-0459-4

32 Gong Y, Zhao X, Wu DI and Liu J: Nuchal-type fibroma of the shoulder: A case report and review of the literature. Oncol Lett 11(6): 4152-4154, 2016. PMID: 27313758. DOI: 10.3892/ ol.2016.4530

33 Poisson M, Ferri J and Schlund M: Mouth floor tumour in an elderly woman. J Stomatol Oral Maxillofac Surg 120(1): 75-76, 2019. PMID: 30389420. DOI: 10.1016/j.jormas.2018.10.009

Received June 10, 2020

Revised July 5, 2020

Accepted July 7, 2020 